\title{
Enfrentamento do fracasso escolar: das práticas vivenciadas aos indicadores validados
}

\author{
Maria José Bastos Martins ${ }^{1}$ \\ Marinê Fecci Batistão Leite ${ }^{2}$ \\ Róbison Benedito Chagas ${ }^{3}$ \\ Sandra do Rocio Ferreira Leal ${ }^{4}$
}

\begin{abstract}
RESUMO
O presente texto trata da análise e avaliação do projeto extensionista: "Enfrentamento do Fracasso Escolar na Educação Básica", o qual se deu a partir da organização coletiva e interdisciplinar dos partícipes do projeto, com o objetivo de trabalho constante e organizado no enfrentamento do fracasso escolar. O projeto é coordenado por professores de Estágio Supervisionado do Curso de Pedagogia - Orientação Educacional e Letras. Participam professores e acadêmicos da UEPG (Universidade Estadual de Ponta Grossa), das licenciaturas, professores, equipe técnico-pedagógica, funcionários, alunos e pais das escolas públicas que aderiram ao projeto numa prática de reflexão, ação, reflexão que, em sua operacionalização, se estende às modalidades de ensino, pesquisa e extensão. Dentre os indicadores validados nesta experiência pedagógica, pontuamos os seguintes: atitude interdisciplinar; interação Universidade / Educação Básica; ação organizada do coletivo escolar; postura político-pedagógica crítica e construtiva; produções científicas; metodologias
\end{abstract}

${ }^{1}$ Professora de Estágio Supervisionado no Curso de Pedagogia / Orientação Educacional da UEPG, Mestre em Educação pela UNICENTRO/UNICAMP.

${ }^{2}$ Professora de Estágio Supervisionado no Curso de Pedagogia / Orientação Educacional da UEPG, Mestre em Educação pela UFPR.

${ }^{3}$ Professor de Metodologia e Prática de Ensino de Português do Curso de Letras da UEPG, Mestre em Literatura Brasileira pela UFSC.

${ }^{4}$ Professora de Metodologia e Prática de Ensino de Português do Curso de Letras da UEPG, Mestre em Educação pela UNICENTRO / UNICAMP.

Olhar de professor, Ponta Grossa, 2 (2):149-160, nov. 1999. 
alternativas; articulação entre ensino, pesquisa e extensão e construção do conhecimento.

Palavras-chave: fracasso escolar, organização das práticas pedagógicas, interdisciplinaridade, construção do conhecimento.

Ao longo de nossa trajetória profissional como professores, convivemos com as nossas contradições, vencendo desafios e sendo checados por eles, porém, sem abandonar os nossos propósitos de construção e reconstrução de uma escola pública compromissada com a emancipação humana.

Temos propósitos comuns como educadores que somos e acreditamos numa educação transformadora, que possa contribuir, juntamente com outras instâncias, para transformações sociais significativas.

O itinerário de cada um é pessoal, pois é produto da história de vida profissional, que é única, assim como a forma como nos posicionamos diante dos fenômenos educacionais revelam as nossas histórias e a forma como enfrentamos os desafios.

Entendemos que o processo educativo, em todos os níveis de ensino, deve estar compromissado com a formação do cidadão.

Diante disso, é necessário que a escola torne-se um espaço, no qual o aluno possa expressar sua cultura, o aprendizado faça sentido na compreensão do mundo em que vive e possa contribuir para torná-lo protagonista na luta por uma sociedade em que a inclusão constitua um padrão de dignidade, exigido para todos os brasileiros.

Práticas educativas isoladas, fundamentadas num modelo de formação do indivíduo com base na fragmentação do conhecimento e das ações e num projeto pedagógico etnocêntrico, mostram-se insuficientes diante dos desafios postos pela globalização e reestruturação da economia.

Assim, discutir a questão da educação brasileira implica, necessariamente, em analisar o problema do fracasso escolar presente, de modo especial, no ensino público e, notadamente, nas camadas mais empobrecidas da população.

Essa problemática tem sido historicamente pontuada como do aluno, numa linha de análise psicológica e individual.

Também as distorções e os preconceitos que existem sobre os alunos das classes populares contribuem extraordinariamente para o fracasso escolar. É necessário aprofundar os estudos para compreender melhor a situação, pois “ ... explicações do fracasso escolar baseadas nas teorias do déficit e da diferença cultural precisam ser revistas a partir do conheci- 
mento dos mecanismos escolares produtivos de dificuldades de aprendizagem”. (PATTO, 1991, p. 340).

Índices do insucesso escolar são observados em todas as séries das escolas públicas brasileiras. As séries iniciais, entretanto, atingem os maiores picos. Objetivando promover um trabalho constante e organizado na busca do enfrentamento do fracasso escolar, na Educação Básica, tendo em vista a parceria estabelecida entre a Universidade Estadual de Ponta Grossa-PR e Colégios Estaduais interessados em participar do projeto e ainda o interesse na articulação com os diferentes níveis de ensino, acadêmicos e professores mobilizaram-se para buscar formas alternativas para a consecução dos objetivos propostos.

Esse projeto de intervenção teve como ponto de partida a análise de dados gerais das escolas públicas estaduais da cidade de Ponta Grossa, no qual foi identificada uma escola que no ano de 1989 matriculou quarenta e quatro alunos numa turma de $5^{\mathrm{a}}$ série e, ao final do ano letivo, todos foram reprovados.

A partir da constatação do fracasso escolar, buscamos propor formas alternativas às existentes, apostando na organização coletiva e interdisciplinar, com a participação de professores, acadêmicos e estagiários dos cursos de licenciatura, professores da Educação Básica, equipe técnico-pedagógica, funcionários, alunos e pais das escolas participantes do projeto.

A proposta fundamenta-se na va- lorização do trabalho coletivo, gestão democrática, clima organizacional favorável, valorização dos diferentes saberes, respeito à individualidade $\mathrm{e}$ características pessoais na maneira de aprender, flexibilidade de construção no processo, relação teoria/prática, estabelecimento de objetivos comuns, imbricamento entre ensino, pesquisa e extensão e articulação entre os níveis de ensino.

\section{A trajetória construída na im- plantação da proposta}

Diante da teoria, da nossa vivência e das nossas observações da escola pública em todos os níveis de ensino, é que firmamos a idéia de desenvolver o projeto extensionista, apostando na possibilidade de desenvolver um projeto discutido, pensado e assumido por todos. O projeto extensionista teve início em 1994 e continua a ser desenvolvido em escolas públicas da rede estadual de ensino.

Numa das escolas expusemos os nossos propósitos de desenvolver, paralelamente ao projeto extensionista, a pesquisa participante, pois segundo NORONHA (1989, p.141)

Torna-se necessário, (...) transformar a "verdade prática" em verdade teórica para que a primeira ganhe um conteúdo revolucionário.

Ou seja o projeto extensionista, ao 
ser refletido na totalidade escolar e comunitária, revelou possibilidade política de transformação da realidade escolar.

Enquanto educadores comprometidos com a educação e a erradicação do fracasso escolar e com a formação dos profissionais da educação em estágio curricular, fundamentados teoricamente numa concepção de educação transformadora, acreditamos que podemos contribuir, a partir da nossa práxis pedagógica, na articulação entre o Ensino Fundamental e o Superior, num processo constante de construção e reconstrução do conhecimento, visando a melhoria do processo ensino-aprendizagem.

Entendemos que a compreensão da prática educativa, que permeia o cotidiano escolar, implica em relacioná-la com os contextos extra e intra-escolares, ou seja, as práticas institucionais, que se relacionam com o funcionamento do sistema escolar e são desenhadas por sua estrutura dominante; as práticas organizativas, que se relacionam com o funcionamento da escola e as práticas didáticas, que se relacionam às ações exercidas pelos professores. Assim sendo, refletem as escolas e são espaços organizados já existentes, antes da existência dos seus atores e, segundo NÓVOA,

... não se limitam a reproduzir as normas e os valores do macro-sistema, mas que também não pode ser exclusivamente investida como um micro universo dependente do jogo dos atores sociais em presença. (1992, p.120)

Nossa função foi a de envolver em postura reflexiva os diferentes segmentos que se inseriram no projeto, numa perspectiva interdisciplinar, visando a operacionalização da proposta pedagógica da escola, sem desconsiderarmos os fatores externos e internos que interferem no processo ensino-aprendizagem, optamos pela focalização dos fatores internos da problemática.

Para a consecução dos objetivos propostos, divulgamos o projeto extensionista aos acadêmicos e professores supervisores do estágio das licenciaturas da UEPG, para a comunidade escolar, dos Colégios com a finalidade de estabelecer, de forma coletiva, as prioridades no encaminhamento das ações, pois segundo PLACCO (1994, p. 15)

O trabalho com o coletivo da escola apresenta desafios que envolvem expectativas, inseguranças, dúvidas e necessidades de agir, de intervir face aos desafios propostos pelas experiências, de modo a refletir sobre as ocorrências da prática escolar, clareando-as e transformando-as na direção da formação do homem necessário à sociedade.

Isto é, a aceitação de desafio no sentido da reversão de posturas auto- 
ritárias que permeiam as relações pedagógicas em direção ao fortalecimento da capacidade de iniciativa transformadora de grupos, antes que de indivíduos isolados.

Coletivamente, construímos o plano de ação, prevendo as atividades mediatas e as imediatas, sabedores da dinâmica das práticas pedagógicas, previmos reuniões semanais com os acadêmicos para a reflexão da prática realizada, fundamentando-nos teoricamente e repensando os próximos encaminhamentos. Com os professores das $5^{\text {as }}$ séries, equipe técnico-pedagógica, acadêmicos, professores da Universidade e coordenadores do projeto, além dos encontros coletivos para o planejamento global, estabelecemos canais de comunicação permanente, com a mediação principalmente das orientadoras educacionais da escola responsáveis pela coordenação pedagógica do colégio, respondendo inclusive pelos encaminhamentos do projeto extensionista naquela realidade.

Essa prática de planejamento vivenciada configurou-se como significativa, no sentido de favorecer a aglutinação dos diferentes segmentos envolvidos e propiciou a reflexão radical e interdisciplinar sobre aquela realidade, onde cada participante contribuiu com o seu saber já reelaborado, considerando a problemática do enfrentamento do fracasso escolar.

Concordamos com FAZENDA (1991, 1997) que cada momento deve ser refletido pelo grupo, sistematizan- do e replanejando, numa atitude interdisciplinar, todos os aspectos devem ser considerados bem como todos os elementos que possam contribuir para que o grupo decida os futuros encaminhamentos. Isto implicou numa crítica do grupo sobre a sua própria ação, através da reflexão sobre a sua prática. Essa crítica efetivou-se basicamente pela tomada de consciência pelo grupo, das distâncias que existam entre as propostas e as ações.

A crítica que teve início pelo confronto dos métodos pedagógicos com os objetivos educacionais desejados, ampliou-se para questões mais profundas que envolveram a organização da escola, da sala de aula e dos alunos, mediados pelos partícipes do projeto, enfrentando os obstáculos advindos das relações de poder, preconceitos, mitos e conflitos, procurando compreendê-los e explicitá-los na abrangência das ações desenvolvidas.

A nossa concepção metodológica no encaminhamento da proposta foi basicamente a de acreditar que a escola e nós nos organizaríamos de forma coletiva, adotando métodos dialógicos e participantes para que pudéssemos refletir e discutir os encaminhamentos. Tivemos resistência "velada", tanto por parte de alguns professores do Colégio, como por parte de acadêmicos que não conseguiram se engajar na proposta. Segundo eles, porque a escola não os recebeu da forma como idealizaram essa recepção, não compreendendo 
que a escola é local de conflito e de contradições e que é nesse campo que poderemos conquistar o nosso espaço e contribuir, como é o caso, para alterar concepções arraigadas sobre o fracasso escolar.

Enfrentando os desafios, fomos avançando e percebendo a segurança crescente do grupo e sendo aprovado pelos pais e a comunidade em geral, pela firmeza dos propósitos, dos novos grupos formados.

O processo vivenciado de permanente clarificação coletiva quanto as metas e ações pedagógicas voltadas à aprendizagem dos alunos, em práticas dinâmicas e conjuntas de planejamento, execução e avaliação para um novo replanejar, mostrou-se eficaz para a quebra de muitas resistências. Esse trabalho participativo possibilitou e impulsionou a atuação dos envolvidos em suas diferentes funções, tendo reflexos positivos no progresso e estudo dos alunos e na formação em serviço de professores e acadêmicos, ampliando as articulações entre o Ensino Fundamental e o Ensino Superior, instituição essa, que deve contribuir para a formação continuada de seus egressos.

As práticas desenvolvidas no projeto extensionista estiveram determinadas pelos diferentes contextos, mas também interferiram neles, alterando concepções e práticas pedagógicas vigentes.

Esse trabalho cooperativo se fez porque professores, acadêmicos, equipe pedagógica e coordenadoras aprenderam, diante das necessidades postas pelos objetivos comuns, articular ações entre níveis de ensino, para dar conta do projeto e da sua execução, fruto do compromisso coletivo, o qual refletiu a opção por um conjunto de valores e critérios que nortearam a ação pedagógica a partir de uma visão contextualizada do processo educativo e de um referencial teórico-metodológico emancipatório, que fundamentou os encaminhamentos. (SAUL, 1988).

Isto significou repensar, à luz do posicionamento adotado, dentre outras, a questão da organização do trabalho pedagógico.

\section{Práticas vivenciadas na exten- são, pesquisa e ensino: a con- cretização de um sonho}

O termo organização pedagógica segundo FREITAS (1998) pode ser interpretado pelo menos em duas direções: por um lado, referindo-se ao trabalho pedagógico do professor em sala de aula, por outro, como o trabalho pedagógico da escola como um todo, que inclui o trabalho do professor.

Essa organização é competência tanto dos profissionais docentes como dos não docentes. Seria ingênuo acreditar que o professor que atua em sala de aula poderia suprir todas as funções que estão fora da sala de aula, mas que nela interferem, o que não significa que este só atue na sala de aula.

A complexidade da organização 
escolar requer a atuação de diferentes profissionais da educação (Orientador Educacional, Supervisor Escolar, Administrador Educacional), que tendo determinadas especificidades, devem cuidar das tarefas relativas à coordenação das atividades na escola, que vão desde o planejamento, execução, avaliação à reconstrução permanente da proposta pedagógica da escola, com a participação da comunidade.

Considerando o exposto, foram estabelecidas diferentes coordenações em parcerias. Na escola, tivemos os Orientadores Educacionais que mediaram a organização, execução e avaliação das práticas pedagógicas quanto a local, horário, espaço para execução das atividades, levantamento de dados, chamamento dos alunos, adesão dos pais, aglutinação dos diferentes atores envolvidos no projeto (professores da série, funcionários e comunidade) e abertura de canais de comunicação no interior da escola.

Nessas perspectivas de objetivos comuns, a direção engajou-se na parceria, viabilizando as condições materiais, tais como: espaço para reuniões pedagógicas, seminários avaliativos, reuniões com os pais e salas de aula para a realização dos estudos complementares ${ }^{5}$ e oficinas pedagógicas $^{6}$.

$\mathrm{Na}$ Universidade e na escola, os professores coordenadores do projeto viabilizaram canais permanentes de comunicação, através de reuniões semanais com os acadêmicos dos Cursos de Licenciatura em Pedagogia, Letras e Matemática e com a participação de professores e equipe técnico-pedagógica das escolas partícipes do projeto, com a finalidade de refletir sobre as ações desenvolvidas, e conseqüentes encaminhamentos.

Os coordenadores, como parte integrante do grupo, tiveram como função básica promover situações que favorecessem, tanto na universidade quanto na escola, o diálogo, a discussão, a busca e a análise crítica, estimulando a iniciativa, criatividade e autonomia na proposição das práticas pedagógicas.

Os professores de estágio, além de coordenadores do projeto, orientaram, acompanharam e avaliaram as atividades desenvolvidas pelos acadêmicos em estágio curricular e/ou voluntário, atendendo as especificidades das áreas; discutiram com os professores regentes alternativas pedagógicas a partir das necessida-

${ }^{5}$ Estudos Complementares - modalidade de estudo em contra-turno, no qual os acadêmicos estagiários assumem diretamente o processo ensino-aprendizagem dos alunos que apresentam defasagem em conteúdos em disciplinas específicas. A orientação é realizada pelos professores supervisores de estágio, fundamentados nas informações dos professores regentes das turmas.

${ }^{6}$ Oficinas pedagógicas - modalidade de estudo, na qual os alunos da educação básica interessados se inscrevem voluntariamente, após divulgação na escola pelos acadêmicos estagiários, os quais definem os temas de acordo com o interesse dos alunos 
des e interesses demonstrado pelos alunos.

Os professores de Língua Portuguesa decidiram que o ponto de partida deveria ser a leitura pois

... o leitor precisa aprender a capacidade básica de reconhecer os signos comuns pelos quais uma sociedade escolheu comunicar-se: em outras palavras, o leitor precisa aprender a ler. (MANGUEL, 1997, p.85)

Se o leitor/aluno precisa aprender a ler, cabe ao leitor/professor ensinar/ viciar o aluno dessa prática. Talvez esteja aí, na prática da leitura, o caminho para destruirmos o "quadro negro" que algumas escolas apresentavam e apresentam, em se tratando de alunos com dificuldades nessa área.

Nessa perspectiva, todo trabalho dos acadêmicos de Letras, no referido projeto, objetivou conscientizar e explicitar o que é leitura de mundo, enfatizando que todo aluno já chega à escola sabendo "ler" o universo que o cerca. Formada tal consciência, o nosso aluno tem condições de entender que ler não é só decodificar palavras, mas compreendê-las e saber falar acerca do que elas dizem, de forma prazerosa, sem a obrigatoriedade de ler e responder "questionários" e "fichas de leitura" que apenas reproduzem o decodificado, e não dão margem ao aluno para refletir sobre o que leu.

Outra preocupação é quanto ao assunto dos textos selecionados. Traba- lharmos com textos humorísticos para que se efetivasse o riso, o engraçado, o prazeroso, enfim, o lúdico. Dessa forma acreditamos que nossos encontros semanais com os alunos perderam um pouco a formalidade e vencemos, assim, o primeiro grande obstáculo do processo ensino-aprendizagem: o distanciamento entre professor, alunos e o mundo que nos cerca.

Enquanto mediadores, orientadores e organizadores do processo ensino-aprendizagem, os acadêmicos de Letras, fundamentados em GNERRE(1978) e outros teóricos da área, desenvolvem "estudos complementares", voltados para a leitura, produção e reestruturação textual. Dessa forma, criam, através de técnicas variadas e criativas, condições favoráveis à produção de textos individuais e coletivos.

Os textos produzidos são, na sua maioria, narrativos e apresentam, inicialmente, dificuldades no registro coerente das idéias, problemas ortográficos, de concordância e pontuação. Esses problemas, do ponto de vista metodológico, são retomados nos encontros destinados à reestruturação coletiva dos textos e, posteriormente, na reescrita individual, sob a orientação dos acadêmicos.

Percebe-se que as dificuldades dos alunos estão atenuadas e que eles, pouco a pouco, estão tornando-se mais criativos e desinibidos.

Além dos estudos complementares, desde 1998, em caráter experimental, estão sendo realizadas ofici- 
nas pedagógicas como alternativas no Enfrentamento do Fracasso Escolar. Trata-se, portanto, de uma postura diferenciada, uma vez que o trabalho é direcionado a todos os alunos da escola, não apenas àqueles que apresentam baixo rendimento escolar.

Em 1998, foram realizados no Colégio Estadual General Osório Ensino Fundamental e Médio no município de Ponta Grossa - PR, as oficinas: "Histórias de vida dos alunos: uma forma alternativa na construção do conhecimento", destinada a alunos das $8^{\text {as }}$ séries; "As várias versões de Chapeuzinho Vermelho", para as $6^{\text {as }}$ séries e "Geometria: pipas, papagaios e outros bichos" (Matemática) para alunos interessados de todas as séries. Neste ano, as oficinas estão sendo realizadas no Colégio Estadual Presidente Kennedy - Ensino Fundamental e Médio no município de Ponta Grossa - PR. No primeiro semestre, ofertou-se a oficina "Re-vendo a TV", destinada a alunos das $7^{\text {as }}$ séries. Para o segundo semestre, estão programadas duas oficinas, ainda sem títulos definidos, que tratarão sobre a vida e obra de Arnaldo Antunes (Ensino Médio) e a respeito dos aspectos históricos, culturais e turísticos da cidade de Ponta Grossa (Ensino Fundamental).

As acadêmicas estagiárias de ori- entação educacional, além de desenvolverem sessões coletivas com todos os alunos das $5^{\text {as }}$ e $6^{\text {as }}$ séries, sobre orientações metodológicas para um estudo eficaz, cujos conteúdos favoreceram a organização dos alunos; assessoraram as orientadoras educacionais nas mediações que se fizeram necessárias; participaram das reuniões pedagógicas, dos Conselhos de Classe, elegeram como temática central de estágio curricular o acompanhamento ao Projeto Correção de Flu$\mathrm{xo}^{7}$, o qual culminou com o trabalho monográfico sobre este programa institucional, vinculado ao enfrentamento do fracasso escolar. Duas acadêmicas do Curso de Pedagogia, uma em estágio voluntário e outra do programa PIBIC/CNpq, subsidiaram a pesquisa participante, em andamento, com as monografias sobre "A demanda da comunidade por escolarização, no contexto histórico do Colégio 31 de Março" e o "Cotidiano da escola no enfrentamento do fracasso escolar nas $5^{\text {as }}$ séries".

Os professores dos Colégios, estimulados pelo clima que se estabeleceu, de aprofundamento teórico e busca de alternativas no enfrentamento do fracasso escolar, se propuseram a desenvolver a temática em estudo no Projeto Vale Saber e Vale Ensinar $^{8}$ e em monografia de curso

${ }^{7}$ Projeto Correção de Fluxo - implantado em 1997 pela SEED - PR. (Secretaria de Estado da Educação), nas escolas públicas, visando adequação dos alunos em relação a defasagem idade-série. ${ }^{8}$ Projeto Vale Saber - implantado pela SEED - PR. (Secretaria de Estado da Educação), com a finalidade de estimular a formação continuada em serviço do professor e equipe técnico-pedagógica. 
de Especialização "lato sensu", em Língua Portuguesa, sob o titulo: "Enfrentamento do fracasso escolar nas turmas de $5^{\text {as }}$ séries do ensino fundamental, na disciplina de Português: uma tarefa possível".

Com base em um farto referencial teórico, desenvolveu-se a pesquisaação, numa das turmas de $5^{\text {a }}$ série, no Colégio Estadual General Osório, em Ponta Grossa - PR, buscando metodologias alternativas que pudessem valorizar a individualidade de cada aluno para os estudos.

A investigação visou, também, evidenciar a necessidade e a importância de se elaborar o planejamento após conhecer bem os alunos, no que se refere a sua vida escolar sócio-cultural, familiar e os seus saberes. Além disso, propôs uma avaliação constante do trabalho desenvolvido e do aprendizado do aluno, o que exige replanejamentos que oportunizarão o aprimoramento do processo ensinoaprendizagem.

Considerou-se, nesse estudo, que o professor deve estar em permanente atitude de pesquisa e observação, pois cada turma apresenta situações novas que exigirão, também, novas metodologias.

Analisando todo o processo vivenciado, através da pesquisa participante, obtivemos indicadores que validam o trabalho realizado e a possibilidade de a escola se organizar no enfrentamento do fracasso escolar.

\section{Indicadores validados na pes- quisa}

Propusemo-nos a enfrentar o fracasso escolar a partir de um trabalho coletivo, no qual levantamos e analisamos os dados da realidade das escolas públicas interessadas, discutimos as questões de encaminhamentos, desvelamos preconceitos e resistências, colocamos nossas crenças e inseguranças para discussão. A reversão do quadro quanto às dificuldades no processo de ensino e aprendizagem é obra de artesanato e isso depende de sensibilidade, paciência, tolerância, ousadia, esforço, dedicação que de nada valerão sem condições favoráveis, que dependem da vontade política dos partícipes e dos espaços conquistados nessa parceria.

Considerando a trajetória percorrida e analisada, apontamos aspectos que julgamos relevantes e que são fundamentais em projetos dessa nature$\mathrm{za}$, os quais foram validados na pesquisa, em relação aos acadêmicos-estagiários, à organização da escola e seus atores, aos alunos e projeto.

Em relação: Aos acadêmicos estagiários, o projeto oferece condições de articulações entre formação acadêmica e realidade prática, pois os acadêmicos-estagiários ${ }^{9}$ se inserem

${ }^{9}$ Acadêmicos-estagiários - o projeto está aberto à participação de acadêmicos das licenciaturas em estágio voluntários e/ou curricular, desde seu ingresso no ensino superior. 
em todas as práticas pedagógicas desenvolvidas na escola, em função de objetivos comuns de enfrentamento às dificuldades no processo ensinoaprendizagem dos alunos.

Ressaltamos a importância da coordenação do projeto na escola ser executada por profissional da educação, que estabeleça a mediação necessária em todas as fases do processo, aglutinando os diferentes segmentos da comunidade escolar (interna e externa), abrindo canais de participação para todos, especialmente dando voz aos alunos e tendo clareza do projeto educativo da escola.

Reafirmamos como significativo o respeito aos diferentes saberes dos partícipes, inclusive do aluno e a inserção nos processos de construção do conhecimento em atitude interdisciplinar, a partir de métodos dialógicos e participantes, em contraposição à exclusão presente em outros paradigmas que fragmentam o ensino, pesquisa e extensão.

A participação dos alunos nos estudos complementares, oficinas pedagógicas e reuniões decisórias, mostrou-se fundamental para que expressem seus interesses e necessidades, fortalecendo a crença de que são capazes de aprender, pela valorização dos seus saberes e crenças conquistados, tornando-se assim, sujeitos da sua aprendizagem.

Também as metodologias alternativas às utilizadas nas turmas de origem, com alternância de atendimentos individuais nas dificuldades espe- cíficas de cada aluno, favoreceram o relacionamento interpessoal entre alunos e professores e a troca de saberes.

Outro fator a ser considerado é a quebra do tempo pré-determinado para a aprendizagem, com turmas formadas de no máximo vinte alunos, bem como a valorização de todo o trabalho realizado, com apresentação para a comunidade interna e externa à escola.

Outra estratégia validada é o sistema de rodízio entre os alunos, com a participação de monitores e abertura, nas oficinas pedagógicas, para todos os alunos interessados, o que contribui para desmistificar que só "alunos atrasados" freqüentam o contraturno.

Quanto ao projeto, é relevante a participação efetiva dos coordenadores enquanto integrantes da equipe de planejamento, desenvolvimento e avaliação do projeto em sua totalidade e especificidades, estabelecendo parcerias e rompendo com a hierarquia em relação a questão saber versus poder.

A possibilidade de inúmeras parcerias, com a consciência de sua própria autonomia para pensar e discutir suas propostas no grupo, cientes que todos constroem conhecimentos, pois estes são engendrados nas relações sociais, em diferentes momentos históricos.

Assim, um projeto de extensão, ensino e pesquisa como este, que ousa propor a ação organizada no enfrentamento do fracasso escolar que se apresenta na Educação Básica, deverá ser permanente avaliado e 
construído, de forma interdisciplinar, e jamais estará pronto e acabado, mas será enriquecido, de acordo com as condições viabilizadas e o nível de consciência a que as pessoas envolvidas ascenderem.

É lançar um olhar inovador, sair dos padrões estabelecidos e ousar novas práticas interdisciplinares, compreendendo que todos podem e devem ter acesso a usufruir dos bens historicamente acumulados, onde o saber se mostra basilar à conquista da cidadania.

\section{REFERÊNCIAS BIBLIOGRÁFICAS}

1 BAMBERGER, Richard. Como incentivar o hábito da leitura. 2. ed. São Paulo : Ática, 1981.

2 BRANDÃO, Carlos Rodrigues. O que é educação. 4. ed. São Paulo : Brasiliense, 1981

3 FAZENDA, Ivani C. Arantes. Metodologia da pesquisa educacional. 2.ed. São Paulo : Cortez, 1991.

4 Práticas interdisciplinares na escola. 4.ed. São Paulo : Cortez, 1997.

5 FREITAS, Luiz Carlos. Crítica da organização do trabalho pedagógico e da didática. Campinas, São Paulo : Papirus, 1995.

6 GNERRE, Maurizzio (1978). Linguagem e poder. In: Subsídios à proposta curricular de Língua Portuguesa para o $2^{\circ}$ grau. vol.IV. Variação lingüística e ensino de língua materna, Secreta- ria de Estado da Educação, SP.

7 GRANATIC, Branca. Redação, humor e criatividade. São Paulo : Scipione, 1997.

8 MANGUEL, Alberto. Uma história da leitura. Trad. Pedro Maia Soares. São Paulo : Companhia das Letras, 1987.

9 NORONHA, Olinda Maria. Pesquisa participante : repondo questões teórico-metodológicas. In: FAZENDA, Ivani. Metodologia da pesquisa educacional. 2.ed. São Paulo : Cortez, 1991.

10 NÓVOA, Antonio (Coord.). As organizações escolares em análise. Lisboa : Dom Quixote. 1992. p. 120.

11 PATTO, Maria Helena S. A produção do fracasso escolar. São Paulo : T. A. Queiroz, 1990. PLACCO, V. M. N. de Souza. Formação e prática do educador e do orientador. Campinas : Papirus, 1994. p. 15.

12 SAUL, A. M. Avaliação emancipatória : desafio à teoria e à prática de avaliação e reformulação de currículo. São Paulo : Cortez : Autores Associados, 1988.

13 SILVA, Ezequiel T. da. Elementos da Pedagogia da Leitura. São Paulo : Martins Fontes, 1988. 